\title{
Editorial Ambio Vol. XXXIX, No. 1, 2010
}

\author{
Elisabeth Kessler
}

Published online: 24 February 2010

(c) Royal Swedish Academy of Sciences 2010

A New Year always signals new beginnings. Ambio is no exception to this rule. As our readers will notice this first issue of the New Year 2010 comes to you from our new publishing partner Springer. After almost 18 very successful publishing years with Allen Press, Inc. Lawrence, KS, USA, the Royal Swedish Academy of Sciences felt that Ambio needed change in order to meet the new challenges on the publishing horizon with a new publishing partner and the choice fell to Springer with whom we look forward to breaking new ground and moving on. This transfer from Allen Press to Springer will not be especially noticeable or affect communications between Ambio and our readers and authors. Submissions of papers can now be made to Springer via their Editorial Manager system at www.editorial manager.com/ambi and Instructions to Authors and other relevant information are available at www.springer.com/ 13280.

In addition to the many articles on a wide variety of environmental subjects that are already in the pipeline for publication 2010, special features to look out for in Ambio this year will be the six articles from outstanding scientists that resulted from the Royal Swedish Academy of Sciences top-level international symposium "Energy 2050" on fossil-free energy options. This symposium was held in October 2009 and was attended by almost 370 international scientists. These articles will be published as a group in an Ambio Special Report under the heading "The World Needs a New Energy Paradigm.” A second Special Report to be published this year will include a selection of the papers presented at the 2009 Royal Colloquium chaired by His Majesty King Carl XVI Gustav of Sweden. The theme of this Colloquium was "Climate Action: Tuning in on Energy, Water and Food Security" and these papers promise very interesting reading.

The United Nations Climate Conference COP15 is over and the Copenhagen Accord is in place. As in previous years following major United Nations' conferences, when Ambio received a large number of papers relating to the conference themes, Ambio is once again looking forward to receiving many articles relating to the climate change issues discussed in Copenhagen. Climate change is affecting and will continue to affect the conditions for life on earth, for which reason, Ambio will continue to welcome and consider for publication articles, reports and synopses on all of the environmental issues at stake.

In 2010, we at Ambio, together with our new partner Springer, intend to continue to provide you with timely information on all of the issues that affect the human environment. Well met for a brave New Year. 